\title{
Recalibrating the spirit level: An analysis of the interaction of income inequality and poverty and its effect on health
}

\author{
Simone Rambotti \\ University of Arizona
}

\begin{abstract}
The publication of The Spirit Level (Wilkinson \& Pickett, 2009) marked a paramount moment in the analysis of health and inequality, quickly attracting a remarkable degree of attention, both positive and negative, both in academic and in public discourse. Following at least 20 years of research, the book proposes a simple and powerful argument: inequality per se, more specifically income inequality, is harmful to every aspect of social life. In order to confirm this idea, the authors present a series of bivariate, cross-sectional associations showing comparisons across countries and within the United States. Despite the methodological limitations of this approach, the authors advance causal claims concerning the detrimental effects of income inequality. They also rule out poverty as a plausible alternative explanation, without directly measuring it. Meanwhile, over the last decade stratification scholars have demonstrated the nonlinear effect of economic factors, especially income, on health. The results suggest that a relative approach is best for analyzing dynamics at the top of the income distribution, whereas an absolute approach seems most appropriate for studying the bottom of the distribution. Consistent with this perspective, here I reanalyze data from The Spirit Level, adding a measure of poverty, in order to control the effect of inequality and explore its interaction with poverty. The findings show that inequality and poverty - which I contend are two interdependent but nonetheless distinct phenomena - interact across countries, such that the detrimental effects of inequality are present or stronger in countries with high poverty, and absent or weaker in countries with low poverty; poverty replaces inequality as the favored explanation of health and social ills across states. The new evidence suggests that income distributions are characterized by a complex interplay between inequality and poverty, whose interaction deserves further analysis.
\end{abstract}

\section{Keywords}

Income inequality; Poverty; Interaction; Life expectancy; Social problems 


\section{Introduction}

The publication of the book The Spirit Level by social epidemiologists Wilkinson and Pickett (2009) marked a pivotal moment in the literature on health disparities. The book, whose main idea is that income inequality has a detrimental effect on many societal and health outcomes, and thus more equal societies are better for everyone, attracted an exceptional degree of attention in both academic and media discourse. Translated into 23 languages, it became a sensation that sold more than 150,000 copies and won high praise from politicians representing the entire political spectrum, including current Prime Minister of the United Kingdom, David Cameron (Booth, 2010; Devich, 2010).

The authors, resting on a Popperian definition of theory testing (Pickett \& Wilkinson, 2015), claim a causal role for inequality and propose that chronic stress is the key mechanism. The vast majority of the evidence provided in The Spirit Level is in the form of cross-sectional, bivariate associations. Wilkinson and Pickett assess the same bivariate relationships in different contexts (comparisons across countries and among US states), and claim that this constitutes a form of control for spuriousness. The reception of the book was not entirely positive. Notable theoretical (Goldthorpe, 2010) and methodological (Beckfield, 2004; Leigh, Jencks, Smeeding, Salverda, \& Smeeding, 2009) criticisms have been raised, stressing the limits of correlational evidence, and suggesting that the relationships could be spurious in multiple contexts. Another problematic point is the dismissal of poverty as alternative explanation. This conclusion is ill advised by the fact that the scholars rule out poverty without having a measure of it, but rather by using a measure of average wealth, the national income per capita (Wilkinson \& Pickett, 2009, p. 20).

While it is important to explore the adverse effects of income inequality, additional research is needed to establish previous claims and to advance the literature. In particular, it is important to consider (1) possible spurious effects of inequality, (2) the direct role of poverty, and (3) the interaction between inequality and poverty. Building on previous work, this paper examines the direct and synergistic effects of income inequality and poverty.

\section{Income, inequality, and health: evidence and debate}

In his classic 1975 piece, Preston acknowledges that the effect of economic factors on health has been identified "at least since biblical times" (1975, p. 231). The first study 
to test the hypothesis that life expectancy is a function of average income and income distribution might date back to the late 1970s (Rodgers, 1979), but the issue became wellestablished in the 1990s, with the publication of several studies that assessed the effects on health of income distribution controlling for gross national product across countries (Wilkinson, 1992), within the US states adjusted by state median income (Kaplan, Pamuk, Lynch, Cohen, \& Balfour, 1996), in the US after adjustment for absolute poverty (Kennedy, Kawachi, \& Prothrow-Stith, 1996), and in the US through a multilevel approach controlling for household income (Kennedy, Kawachi, Glass, \& Prothrow-Stith, 1998). The psychological explanation was immediately advanced, despite scholars quickly recognizing the association between underinvestment and inequality (Davey Smith, 1996).

The productivity of this line of research has not seemed to have ceased. In the 20 years preceding the publication of The Spirit Level (Wilkinson \& Pickett, 2009), more than 100 articles explored the association between health and economic inequality (Mullahy, Robert, \& Wolfe, 2008; Leigh et al., 2009). After 2009, the debate crossed the boundaries of social epidemiology and the academic world: the general public and the media joined the discussion.

An overview of research on stratification contributions to health shows that analysts mainly investigated mainly the impact of economic conditions (income or income inequality) on health, and devoted less attention to the opposite direction of the relationship. Broadly, three approaches emerged: (1) the absolute income hypothesis, (2) the relative income hypothesis, and (3) the income inequality hypothesis (Mullahy et al., 2008; Leigh et al., 2009). The first approach concentrates on the diminishing returns of individual income: earning an extra dollar is more beneficial at the lower end of the income distribution. The second approach connects social ranking to mortality/morbidity through the gradient effect (Adler et al., 1994; Marmot et al., 1991): social status is symbolic, and individuals compare themselves to others, with unfavorable relative comparisons being harmful. The third perspective suggests an adverse effect of aggregated levels of income inequality, even after controlling for individual income.

The relative income hypothesis implies a critical point: not only material economic conditions (e.g., poverty), but also social psychological processes (e.g., stress) can impact health. Thus, one can assume that "Health effects at the upper part of the distribution may more strongly reflect relative status, while at the lower part they may be more linked to absolute deprivation" (Adler \& Newman, 2002, p. 62). Hence, it is crucial to 
understand that income inequality and poverty can operate in a simultaneous but different manner: they are undoubtedly interconnected but nevertheless distinct phenomena, which may affect different strata of population in discernibly different ways.

The work of Wilkinson and Pickett can be referred to as the income inequality approach, but their mechanism is consistent with the implication of the relative income hypothesis just described: in fact, the proposed causal relationship between income inequality and health/societal outcomes is mediated by chronic stress.

The three theoretical perspectives seen above produce different results through the application of a variety of levels of analysis, methods, and data. One important result is the robust nonlinear association between income and health (Mullahy et al., 2008; Leigh et al., 2009). The stratification scholar is familiar with the principal mediating factors of the relationship, such as race and neighborhood context. Another key finding is the relationship between income inequality and health, which is, however, less robust and more controversial (Beckfield, 2004; Kawachi, Subramanian, \& Almeida-Filho, 2002; Kondo et al., 2009; Leigh et al., 2009; Lynch et al., 2004; Mullahy et al., 2008). In the most comprehensive review to my knowledge, Kondo et al. (2009) carry out a metaanalysis of 9 cohort studies (59,509,857 subjects) and 19 cross-sectional studies $(1,280,211$ subjects), suggesting a "modest excess risk of premature mortality and poor self-rated health" (2009, p. 8) associated with income inequality, and the existence of a threshold effect upon which the negative consequences of inequality are remarkably strong (Gini $\geq$ 0.3). Beckfield (2004) analyzed the relationship across countries and over time, finding limited empirical evidence for the adverse role of income inequality. Analyses based on panel data are also mixed: some support the income inequality hypothesis with regard to mental distress (Wood, Boyce, Moore, \& Brown, 2012) and happiness (Layard, Mayraz, \& Nickell, 2010); others find no effect of inequality on mortality (Gerdtham \& Johannesson, 2004), or self-reported health (Lorgelly \& Lindley, 2008). These results overall suggest caution in assessing the robustness of the effect of income inequality on mortality/morbidity.

Additional disagreement may arise concerning the mechanisms linking inequality and health. Again, three perspectives arise: (1) the psychological pathway proposed by Wilkinson and Pickett; (2) the social capital hypothesis (Kawachi \& Berkman, 2000; Kawachi, Kennedy, Lochner, \& Prothrow-Stith, 1997) that mediates between the psychological and the structural levels; (3) a neo-material explanation that focuses on the 
material and social environment of the places characterized by high inequality and on the mediating role of public investment. Scholars who take this perspective (Mellor \& Milyo, 2002; Soobader \& LeClere, 1999) hypothesize that the adverse effect of inequality may be true only for the poor. Consistent with this latter perspective, analyses of contextual income inequality in Norway using administrative data (Dahl, Ivar Elstad, Hofoss, \& Martin-Mollard, 2006; Elstad, Dahl, \& Hofoss, 2006) observe adverse effects of relative income only (or particularly) on the most disadvantaged social groups. Explicit tests of the mechanisms favored the role of status anxiety and trust over spending (Elgar, 2010; Elgar \& Aitken, 2011; Layte, 2012), although the mechanisms are not mutually exclusive and expenditure is a crude measure of social welfare (Kenworthy, 2011; Kenworthy \& Pontusson, 2005).

In recent years most studies have examined the effects of income inequality, but there are some notable exceptions, rooted in the classic body of literature that emphasizes the difficulty of escaping poverty in a segregated neighborhood (Massey \& Denton, 1993; Wilson, 1987). Taking advantage of the randomized housing mobility experiment Moving to Opportunity, Ludwig et al. $(2011,2012)$ show that moving from a high-poverty to a low-poverty neighborhood has long-term beneficial effects on measures of physical health, such as diabetes and obesity (Ludwig et al., 2011), and on subjective well-being (Ludwig et al., 2012), despite not improving adult economic self-sufficiency. One might think that residential segregation is in turn affected by inequality, but this is not necessarily the case. In fact, evidence suggests that income inequality may even reduce spatial segregation of low-income households and that rising income inequality cannot explain the increase of poverty segregation in the United States (Reardon \& Bischoff, 2011). At a different level of analysis, Fritzell et al. (2013) look at the role of relative poverty over time across 26 countries (affluent countries and some post-socialist Eastern European countries), and find that poverty has a detrimental effect on death risk also in affluent countries.

This evidence supports the idea that inequality and poverty are distinguishable social facts linked by a complex interplay. Indeed, "the relationship between inequality and poverty is complex and not mechanical" (Ringen, 1986, p. 126). I elaborate on this point in the following section. 


\section{Poverty and inequality: dependent but distinct}

It is not my intent to affirm that poverty is independent of inequality and vice versa, but I claim that poverty is not the same as inequality. I also contend that conjoint use of aggregate measures of poverty and income inequality allows for a more nuanced understanding of the impact of socio-economic factors on health. One way to formally analyze this interplay is to explore the statistical interactions of the measures of poverty and inequality. Such an attempt, as carried out in this study, is to my knowledge absent in the literature, and relies on some assumptions that are analyzed in the following paragraphs.

Poverty is not inequality, and is not simply low income

"Poverty is not just one aspect of inequality, but the unacceptable face of extreme inequality" (Alcock, 2006, p. 7). The Supplementary Benefit Commission in Britain defines poverty as "a standard of living so low that it excludes and isolates people from the rest of the community. To keep out of poverty, they must have an income which enables them to participate in the life of the community" (1979, p. 2). This definition stresses two points: (1) income is necessary; (2) poverty is more than low income; indeed, it is separation from the community. Poverty is a multidimensional concept (Bradshaw \& Finch, 2003; Finch \& Bradshaw, 2003) that may be usefully conceived of as social exclusion (Alcock, 2006; Barry, 2002; Brady, 2003; Levitas, 2005; Lister, 2004; Townsend, 1962, 1987). This conception ideally requires a level of sophistication in the measurement that is incompatible with the severe constraints set by macro-comparative analysis. In fact, Alcock (2006) calls for qualitative measures as an aid to more fully understand the experienced meaning of poverty, and Ringen (1986), despite being critical of the use of income as an unique measure, deems as unrealistic a full analysis of all the causes of, or remedies for poverty (welfare, public investment, schools, families, neighborhoods, culture, and so forth). While a mixed-method approach that combines information from secondary data, surveys, and qualitative analysis is possible within one geographical context, this task would be daunting in comparative national analysis. Poverty is a complex phenomenon not captured completely by measures based on income. However, I claim that this approach is still valuable. In fact, income does say something about poverty and exclusion: "Widely used indexes of 'poverty' take it as being represented by an income half that of the median. It seems plausible that something like this income is also necessary for full participation" (Barry, 1998, p. 22). 
Relative poverty, absolute poverty and income inequality

In this study I use different measures of poverty: the relative poverty rate at the international level, and the absolute poverty rate within the US. The choice is constrained by data availability. Consistent with Wilkinson and Pickett, I use data provided from renowned organizations (Luxemburg Income Study; US Census) in order to reject the criticism of cherry-picking data that better fit my hypotheses. There is much debate as to whether one should use a relative or an absolute measure. However, both absolute and relative measures grasp a dimension of poverty as headcount (the number of people living below a line), which catches the breadth but ignores the depth of poverty among the poor. In this respect, the measures are more similar than they may appear. Indeed, some researchers affirm that "there is no such thing as absolute poverty" (Ringen, 1986, p. 123), and that describing the US measure as absolute is "very misleading" (Ringen, 1986, p. 125). Measures of inequality, on the other hand, give a sense of the income gap across the entire population, or between specific percentiles. I contend that using measures of poverty (whether relative or absolute) and inequality together maximizes the chance to capture both the depth and the breadth of the income distribution: this conjunct approach adds complexity to the model, and benefits the analysis. In fact, I believe that societies can be unequal in different ways. Thus, studying inequality should not be just a question of how much unequal a society is, but how that society is unequal, how inequality is shaped, where this inequality is coming from. Inequality can have a more or less topheavy nature. The center of the income distribution can be more or less far from the top or the bottom of it. Breadth and depth can be combined in all possible ways. These different combinations can be associated with health and societal outcomes in different ways. This is exactly what the data show. Before moving to the systematic analysis I show a short comparison between two English-speaking, ideal-typical liberal welfare states (Esping-Andersen, 1990) universally considered highly unequal countries: the UK and the US. They present comparably high level of income inequality (as measured by the ratio p80/p20): UK=7.17, USA=8.55. However, they have very different poverty rates (as measured by the relative poverty rate as $40 \%$ of median income): $\mathrm{UK}=5.22$, and $\mathrm{USA}=11.25$. Their outcomes are also very different: $\mathrm{UK}=78.20$, and $\mathrm{US}=77.10$ for life expectancy (approximately 1 standard deviation in the data set of 23 countries used by Wilkinson and Pickett); UK=0.79, and US=2.02 for the index of health and social problems (approximately 1.7 standard deviations). 
By this point, I hope to have convinced the reader that absolute and relative poverty rates are similar to the extent that they measure poverty as headcount, that they are useful despite providing only a partial picture of poverty, that inequality and poverty are conceptually and operationally distinguishable, although clearly dependent, and that the combined use of their measures offers valuable insights to comparative analysis of social ills.

\section{Data and methods}

\section{Data}

Data for this study come from the data set collected by Wilkinson and Pickett and available on the Equality Trust website (Equality Trust Website, n.d.). I chose to utilize the original data set of The Spirit Level without replacing any measure, in order to avoid the critique of choosing data that give the desired result. Wilkinson and Pickett use data provided by esteemed organizations, rather than creating new measures, exactly for the same reason.

In addition to the measures employed in their study, I added one variable, the national (source: the Luxembourg Income Study) and state (source: the US Census statistics) poverty rate. Further, I created an interaction term between these measures and the level of inequality.

\section{Measures}

The measures of income inequality are those chosen by Wilkinson and Pickett: the 80/20 ratio provided by the UN Human Development Report for the international comparisons (time period: 2003-06), and the 1999 Gini index for the state comparisons.

For the international comparison, the Luxembourg Income Study (LIS) provides three measures of relative poverty, which are "by definition, closely related to inequality" (Wilkinson \& Pickett, 2009, p. 23). However, these measures, although somewhat redundant, may be telling. In order to minimize their redundancy, consistent with Fritzell et al. (2013) I chose to use the most conservative measure of relative poverty, which indicates the percentage of people living under $40 \%$ of the median household income. The time period is 2003-06, with two exceptions: LIS has data for Belgium in 2000 and for Japan in 2008. The LIS database has no data for New Zealand, Portugal, and Singapore, which for this reason are missing in my analysis. I repeated the analysis on another range, 1992-2001 (in this case Japan is also missing): the results, not reported here, are 
comparable. For the comparisons within the US, I used the 1999 absolute poverty rate for each state from the US Census statistics.

Table 1 shows the correlations between the three measures of relative poverty and income inequality. Consistent with my expectations, relative poverty as $40 \%$ of the median income has the lowest correlation with income inequality.

Table 1 - Correlations among inequality and relative poverty

\begin{tabular}{lllll}
\hline & $\begin{array}{l}\mathbf{8 0} \mathbf{2 0} \text { ratio } \\
(\mathbf{U N})\end{array}$ & $\begin{array}{l}\text { Rel. Poverty } \\
\mathbf{4 0 \%} \text { (LIS) }\end{array}$ & $\begin{array}{l}\text { Rel. Poverty } \\
\mathbf{5 0 \%} \text { (LIS) }\end{array}$ & $\begin{array}{l}\text { Rel. Poverty } \\
\mathbf{6 0 \%} \text { (LIS) }\end{array}$ \\
\hline $\begin{array}{l}\text { 80/20 ratio } \\
\text { (UN) }\end{array}$ & 1.0000 & & & \\
$\begin{array}{l}\text { Rel. Poverty } \\
40 \% \text { (LIS) }\end{array}$ & 0.6735 & 1.0000 & & \\
$\begin{array}{l}\text { Rel. Poverty } \\
50 \% \text { (LIS) }\end{array}$ & 0.7221 & 0.9626 & 1.0000 & \\
$\begin{array}{l}\text { Rel. Poverty } \\
60 \% \text { (LIS) }\end{array}$ & 0.7316 & 0.9119 & 0.9807 & \\
\hline
\end{tabular}

Assessing whether the choice of indicators of inequality matters, Kawachi and Kennedy (1997) showed that all indicators were very highly correlated $(R \geq 0.94)$. If the relative poverty rate is only a measure of inequality, one should expect similar coefficients. In this case, however, the correlation is decidedly lower. As for the US states, the correlation between absolute poverty rate and the Gini index is 0.6577 : poverty and inequality are strongly but not perfectly correlated. This reinforces the idea that although interdependent, poverty and inequality are not only analytically distinct, but empirically distinct.

I focused on two outcomes: life expectancy at birth, a classical measure of mortality at the aggregate level, and the index of health and social problems, an aggregate measure created by Wilkinson and Pickett combining many of the outcomes considered in The Spirit Level. The index is the variable that best correlates with inequality in both contexts of the original study (Wilkinson \& Pickett, 2009, p. 284). Israel and Singapore have no data on the index. For further information about the creation of the index I reference the book and the Equality Trust website, section "The Spirit Level", subsection 
"Notes on statistical sources and methods". Table 2 shows the descriptive statistics of the measures used in my analysis.

Table 2 - Descriptive statistics

\begin{tabular}{|c|c|c|c|}
\hline Variable & $\mathrm{N}$ & Mean & Std. Dev. \\
\hline \multicolumn{4}{|c|}{ International Comparison - Outcome: Life Expectancy } \\
\hline Life Expectancy & 20 & 78.68 & 1.10 \\
\hline Income Inequality (Ratio 80/20) & 20 & 5.50 & 1.33 \\
\hline Relative Poverty (40\% of Median Income) & 20 & 5.51 & 2.71 \\
\hline Interaction Poverty $\times$ Inequality & 20 & 32.63 & 23.01 \\
\hline \multicolumn{4}{|c|}{ International Comparison - Outcome: Index of Health and Social Problems } \\
\hline Index of Health and Social Problems & 19 & -0.08 & 0.68 \\
\hline Income Inequality (Ratio 80/20) & 19 & 5.44 & 1.33 \\
\hline Relative Poverty (40\% of Median Income) & 19 & 5.16 & 2.28 \\
\hline Interaction Poverty $\times$ Inequality & 19 & 30.00 & 20.33 \\
\hline \multicolumn{4}{|c|}{ State Comparison } \\
\hline Life Expectancy & 50 & 77.02 & 1.40 \\
\hline Index of Health and Social Problems & 50 & 0.00 & 0.75 \\
\hline Income Inequality (Gini Index) & 50 & 0.45 & 0.02 \\
\hline Absolute Poverty & 50 & 11.94 & 3.12 \\
\hline Interaction Poverty $\times$ Inequality & 50 & 5.37 & 1.61 \\
\hline
\end{tabular}

\section{Analytic strategy}

I present four OLS regression models for each outcome, each model including the following independent variables:

Table 3 - Models

\begin{tabular}{ll}
\hline & Independent Variables \\
\hline Model 1 & Income Inequality \\
Model 2 & Poverty \\
Model 3 & Income Inequality; Poverty \\
Model 4 & Income Inequality; Poverty; Interaction Inequality*Poverty \\
\hline
\end{tabular}


In order to assess the sensitivity of the analysis to outliers, I compute a jackknife estimation of the parameters (Quenouille, 1949, 1956; Tukey, 1958). The procedure drops one observation at a time from the sample, and computes the estimator of the parameters: the jackknife estimator is equal to the average of all the subsample estimators. The jackknife estimation alters only the standard errors, which in turn affect the values of $t$ and P. I also checked the robustness of the relationships utilizing a different measure of poverty at the international level, the percentage of people living under $50 \%$ of the median household income, and a different measure of inequality at the state level, the ratio p90/p10 for the total annual individual income (Guetzkow, Western, \& Rosenfeld, 2007).

I formulate two alternative hypotheses, both of which cannot be true simultaneously:

H1) Poverty interacts with inequality: the interaction is significant and negatively associated with life expectancy/positively associated with the index of health and social problems, and the effect of inequality on the outcome is stronger in high-poverty areas than in low-poverty areas;

H2) Poverty replaces inequality: the interaction is statistically nonsignificant and the effect of inequality becomes statistically nonsignificant when estimated together with the effect of poverty; poverty is significant and negatively associated with life expectancy/positively associated with the index of health and social ills. The null hypothesis is that only inequality has a significant effect on both the outcomes, in both the contexts, and across all the models.

\section{Results}

Table 4 shows the results from the analysis on life expectancy for the international comparison. 
Table 4 - Effect of Income Inequality and Poverty on Life Expectancy (International)

\begin{tabular}{lllll}
\hline Life Expectancy & Model 1 & Model 2 & Model 3 & Model 4 \\
\hline Income Inequality & -0.294 & & $-0.605^{*}$ & 0.124 \\
& $(0.182)$ & & $(0.227)$ & $(0.368)$ \\
Poverty & & 0.027 & 0.226 & $0.986^{* *}$ \\
& & $(0.095)$ & $(0.111)$ & $(0.336)$ \\
Inequality $\times$ Poverty & & & $-0.124^{*}$ \\
& & & & $(0.052)$ \\
Constant & $80.292^{* * * *}$ & $78.528^{* * *}$ & $80.755^{* * *}$ & $76.599^{* * *}$ \\
& $(1.029)$ & $(0.582)$ & $(0.977)$ & $(1.958)$ \\
Adjusted R2 & 0.08 & -0.05 & 0.21 & 0.38 \\
N & 20 & 20 & 20 & 20 \\
\hline Note: SE in parenthesis; ${ }^{*} p<0.05 ; * * p<0.01 ; * * *$ & $p<0.001$ (two-tailed t-tests).
\end{tabular}

The findings are compatible with hypothesis 1 . It is important to notice that in Model 1, once New Zealand, Portugal, and Singapore are removed from the analysis, the effect of income inequality is statistically nonsignificant. Poverty is also nonsignificant in Model 2. In Model 3, when poverty and inequality are considered together, inequality is the only significant variable, with a negative effect on life expectancy. In Model 4, however, the interaction term is significant and negatively associated with life expectancy. Model 4 also presents a remarkable improvement in explained variation: the adjusted Rsquared is $38 \%$ compared to $8 \%$ in Model 1 . As predicted, poverty and inequality are connected phenomena, and the interaction term reproduces at the collective level the nonlinearity, consistently found in the literature at the individual level, that characterizes the association between economic factors and mortality.

The jackknife standard error of the interaction term is 0.069 , which yields a t-value of -1.79 . For the two-tailed t-test, $\mathrm{P}$ is 0.089 , above the accepted standard of 0.05 . However, my hypotheses - which were suggested by much previous empirical evidence have a specific direction: I expect the interaction of inequality and poverty to have negative effect on life expectancy. Thus, a one-tailed t-test would be appropriate, and it would halve the level of significance of the interaction to a value (0.045) just below the standard of 0.05 .

To have an intuitive sense of how the interaction works, it is useful to show the 
relationship graphically. My prediction is for inequality to have an adverse effect only when poverty is high, or in any case to have a stronger effect when poverty is high. To test this hypothesis, I split the sample in two subsets: countries with high poverty (values above 0 on the standardized measure of poverty), and countries with low poverty (values below 0). In the following figure, it is possible to see the relationship between income inequality and life expectancy in the form of three regression lines: the gray one for all the cases, the solid black one for countries with low poverty, and the dashed black one for countries with high poverty.

Figure 1 - Life Expectancy by Income Inequality, per Poverty Rate

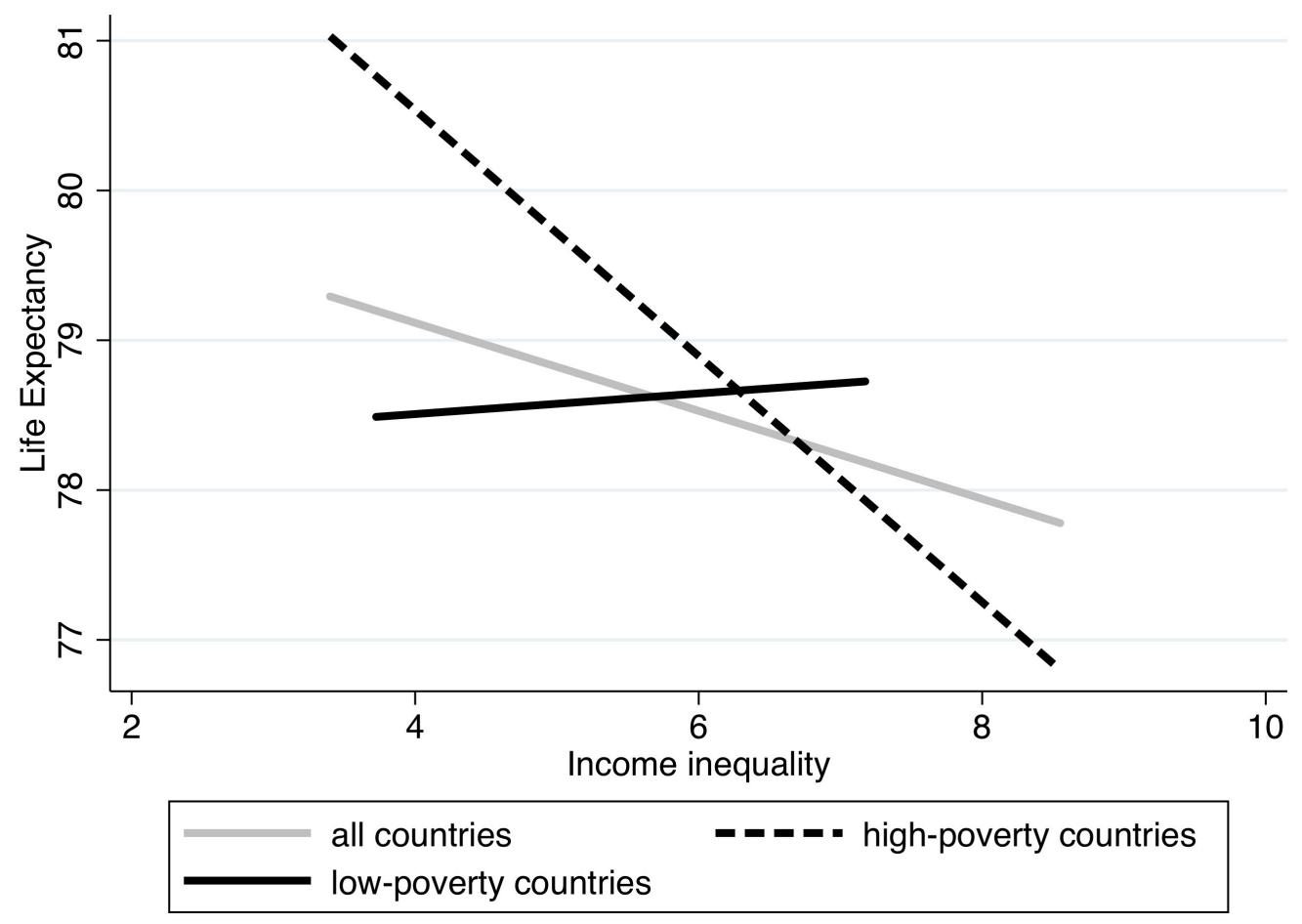

Consistent with my prediction, the line - initially not very steep indeed - becomes much steeper for high-poverty countries, but almost flat for low-poverty countries. This suggests that inequality is detrimental to life expectancy only in countries with high poverty, while it is irrelevant in countries with low poverty. The reader might want to see the distribution of the cases, aside from the regression lines. Figure 2 shows the negative relationship between life expectancy and income inequality only in countries with high poverty: 
Figure 2 - Life Expectancy by Income Inequality, only high-poverty countries

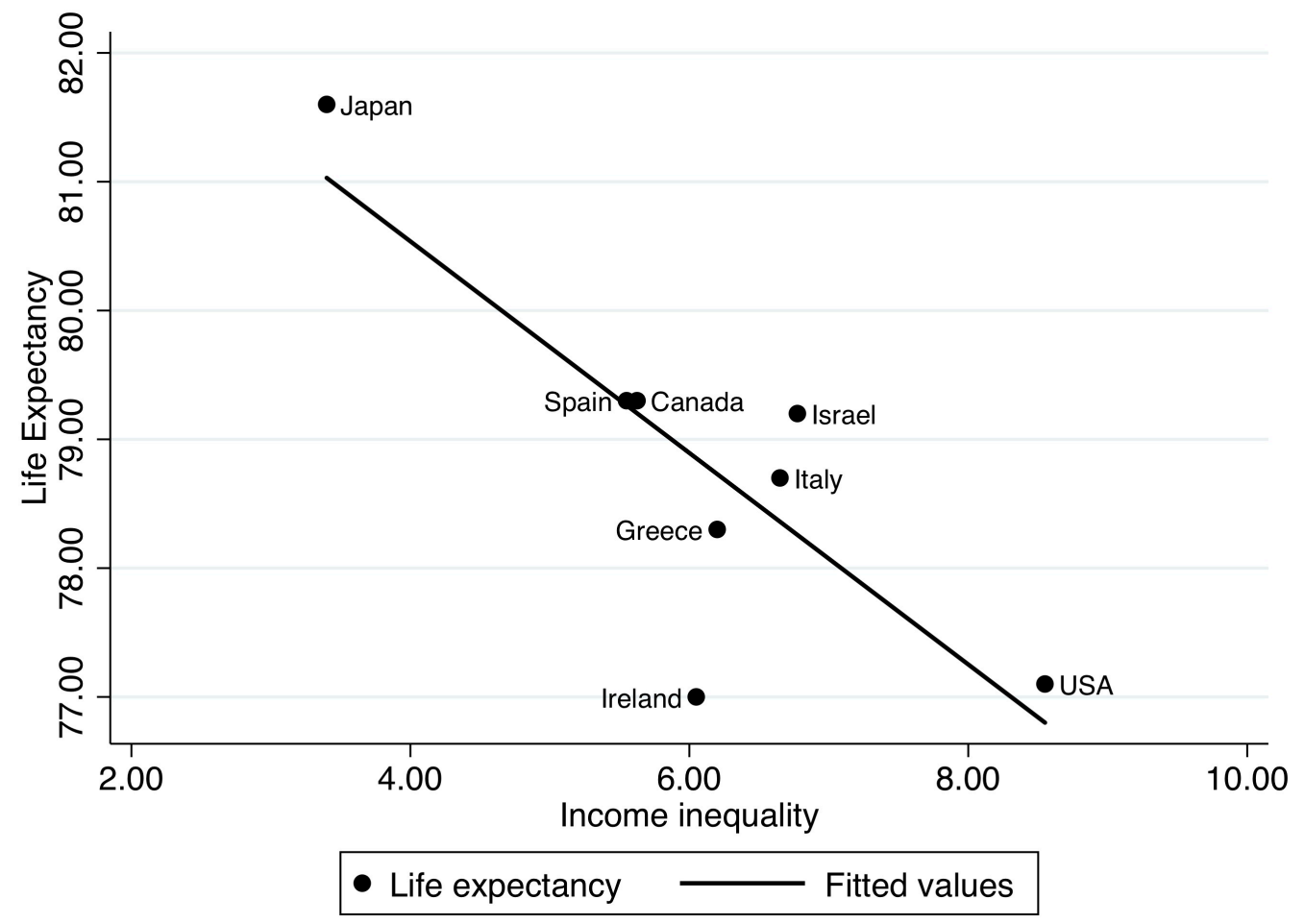

Figure 3 shows the lack of relationship between life expectancy and income inequality in the countries characterized by a low level of poverty. The range of inequality seems to be wide enough to produce a potential effect, given that it ranges from the egalitarian, social democratic Scandinavian countries to the highly stratified, liberal Australia and UK. It is particularly interesting to notice how an important variation in life expectancy occurs just on the lowest end of the range of income inequality. In fact, the four Scandinavian countries, the most egalitarian in this set, have very different outcomes: Sweden has by far the longest life expectancy, and Denmark the lowest. The two countries have a gap of 3.50 years in life expectancy, which is a remarkable difference if we consider that the standard deviation of life expectancy is 1.10: in fact, Denmark has the lowest life expectancy in the whole set of countries, even lower than the US. Norway and Finland fall somewhere in between. 
Figure 3 - Life Expectancy by Income Inequality, only low-poverty countries

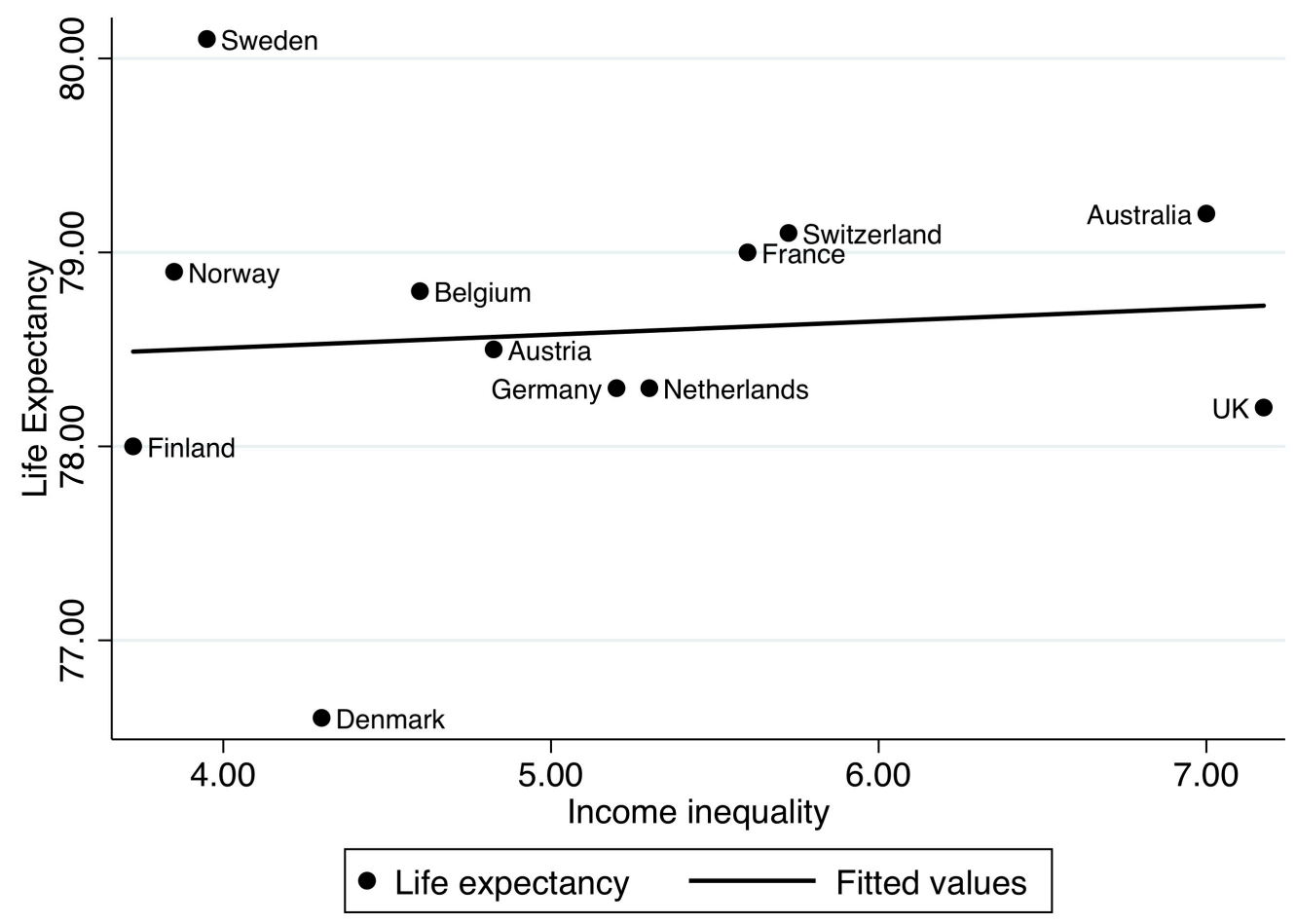

These figures are comparable to figure 2 in De Vogli et al. (2005): only Belgium seems slightly different, more unequal but with the same life expectancy. The authors, however, use another measure of inequality (the Gini index). In the robustness check with the $50 \%$ relative poverty measure (more highly correlated with income inequality), the interaction terms does not reach statistical significance, but the graphical analysis shows a very similar pattern.

Table 5 shows the results of the international comparison using the index of health and social problems (HSP) as outcome: 
Table 5 - Effect of Income Inequality and Poverty on the Index of HSP (International)

\begin{tabular}{lllll}
\hline Index of HSP & Model 1 & Model 2 & Model 3 & Model 4 \\
\hline Income Inequality & $0.435^{* * *}$ & & $0.432^{* * *}$ & 0.048 \\
& $(0.065)$ & & $(0.091)$ & $(0.122)$ \\
Poverty & & $0.176^{* *}$ & 0.003 & $-0.378^{* *}$ \\
& & $(0.059)$ & $(0.053)$ & $(0.109)$ \\
Inequality $\times$ Poverty & & & $0.064^{* *}$ \\
& $-2.447^{* * *}$ & $-0.988^{* *}$ & $-2.443^{* * *}$ & $-0.017)$ \\
Constant & $(0.361)$ & $(0.329)$ & $(0.377)$ & $(0.634)$ \\
& 0.71 & 0.31 & 0.69 & 0.83 \\
Adjusted R2 & 19 & 19 & 19 & 19 \\
N & & & & \\
\hline Note: SE in parenthesis; ${ }^{*} p<0.05 ; * * p<0.01 ; * * * p<0.001$ & (two-tailed t-tests).
\end{tabular}

Once again in this case the results are consistent with hypothesis 1 . Income inequality is now significant in Model 1, as is poverty in Model 2; both have a positive association with the index of social ills. In Model 3 the effect of inequality is still significant and positive, while poverty has no effect. Finally, in Model 4 the interaction term is significantly and positively associated with the outcome: the more inequality and poverty, the more problems. The explained variation in Model 4 increases to $83 \%$, from $71 \%$ in Model 1. The jackknife standard error of the interaction coefficient is 0.022 , yielding a t-value of 2.90 and consequent $\mathrm{P}$ of 0.01 ; the effect of the interaction term is indeed robust. Figure 4 shows the relationship inequality/index of HSP for the three sets of countries: 
Figure 4: Index of HSP by Income Inequality, per Poverty Rate

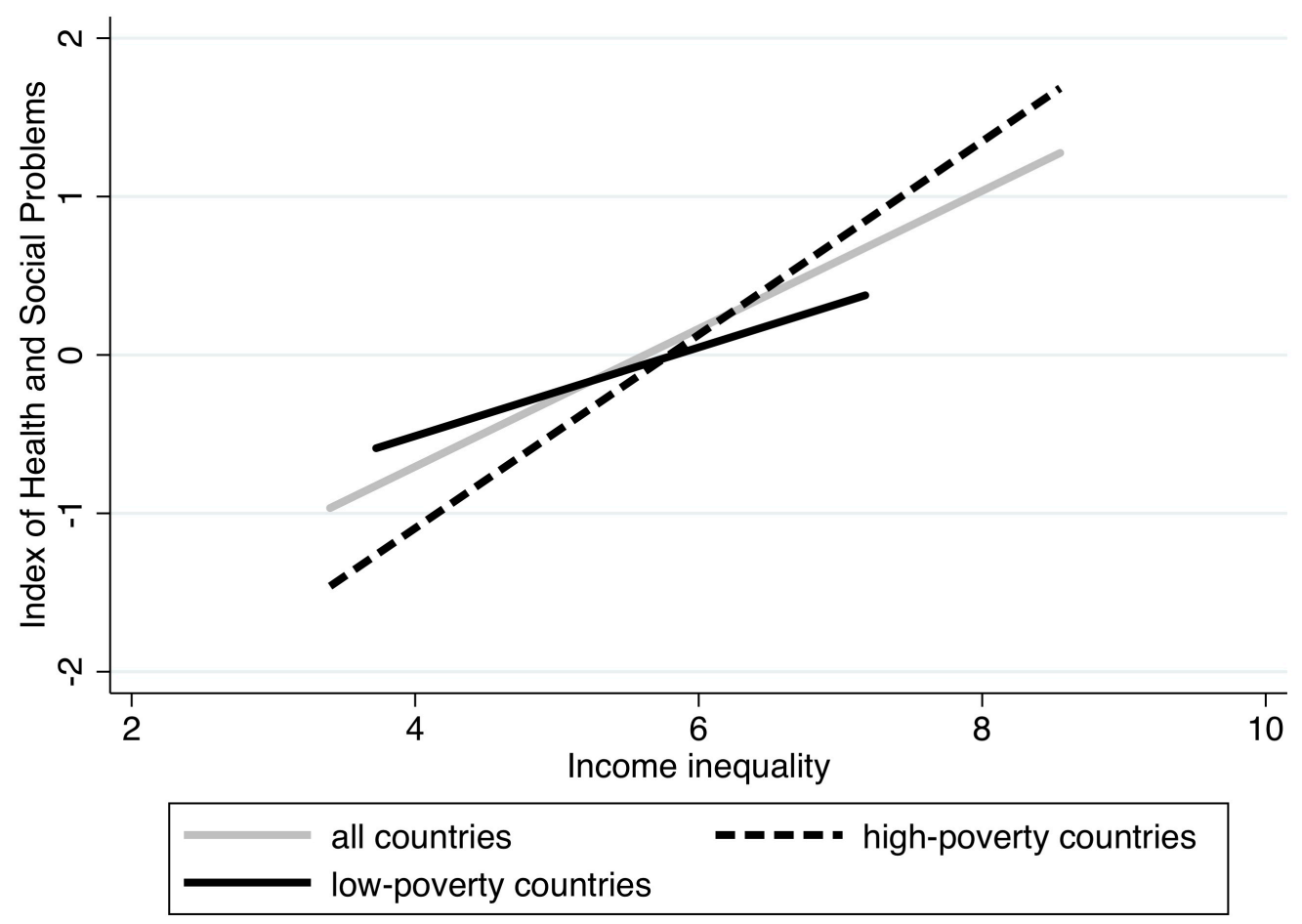

The original regression line with all the countries is quite steep in this case. Although the line for low-poverty countries does not become quite as flat as that in Figure 1, there is still an evident decrease of the effect. The line for the high-poverty countries, however, becomes steeper. Thus, consistent with hypothesis 1 , the evidence suggests that inequality has an adverse effect on life expectancy only when poverty is high, and has a stronger adverse effect on the index of HSP when poverty is high. Figure 5 shows the effect of income inequality on the index of HSP only for the countries with high poverty: 
Figure 5 - Index of HSP by Income Inequality, only high-poverty countries

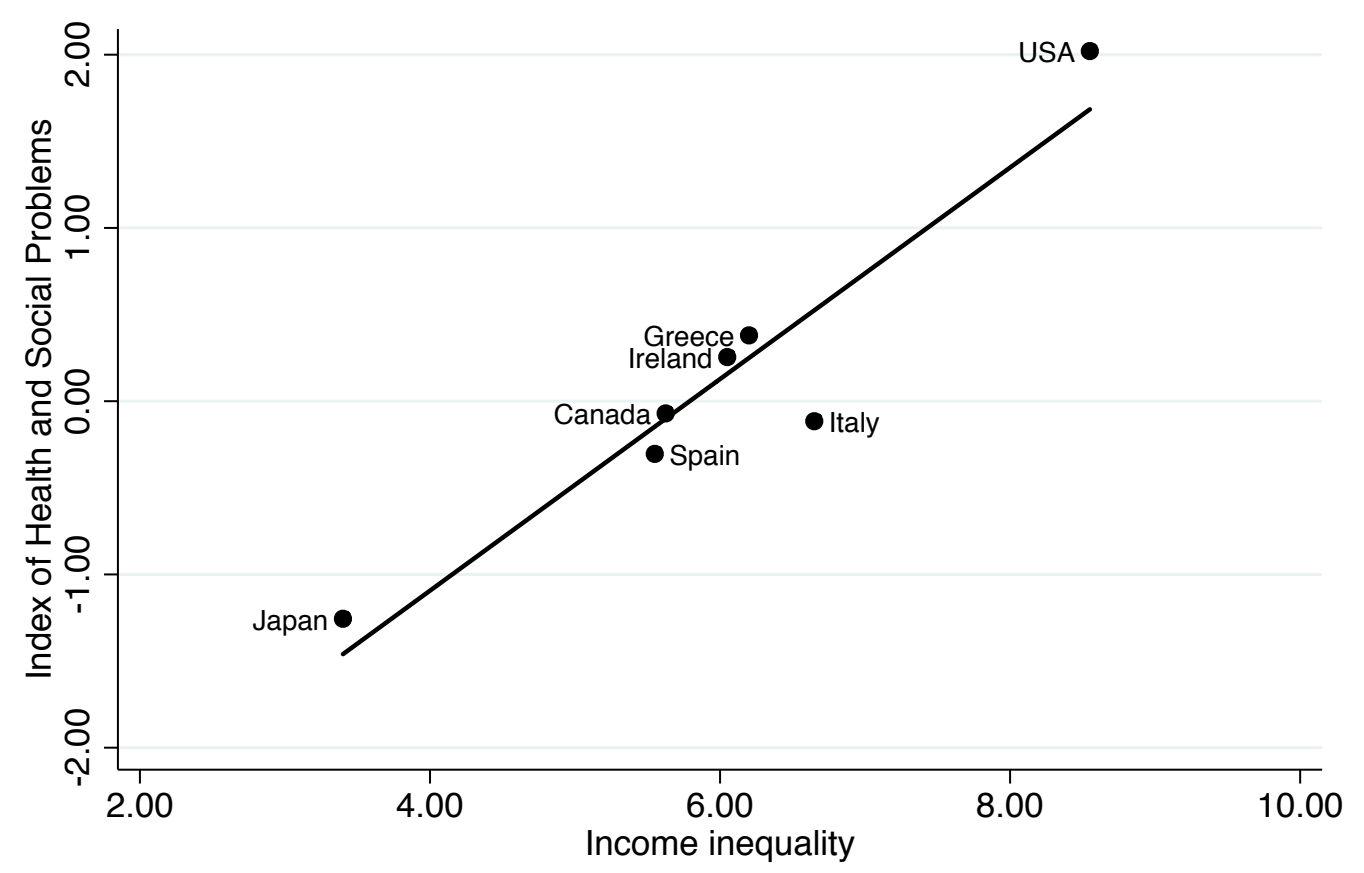

- Index of health \& social_problems — Fitted values

The relationship is very clear and strong, in fact most countries fall almost on the regression line. Figure 6 shows the same information for the low-poverty countries: 
Figure 6 - Index of HSP by Income Inequality, only low-poverty countries

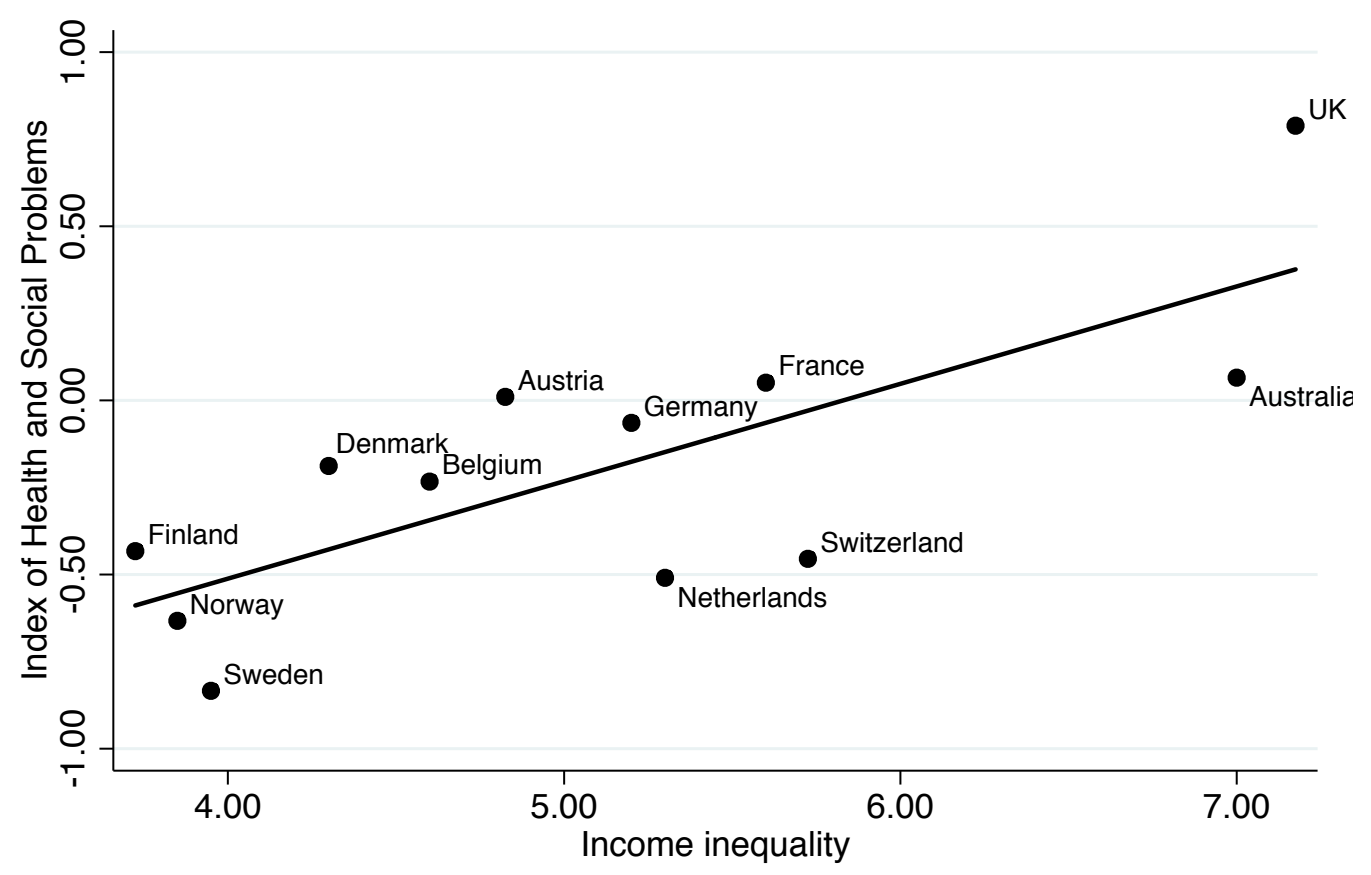

- Index of health \& social_problems — Fitted values

The relationship is still evident, although clearly weaker than that seen in the high-poverty countries. In fact, I do not report the full table here, but I estimated separately the effect of income inequality on the index of HSP (i.e., Model 1) for both sets of countries: the effect of income inequality is significant in both cases, but for the highpoverty countries $(b=0.611 ; p=0.001$; adjusted $r$-squared $=0.87)$ it is more than twice as strong as for the low-poverty countries $(b=0.280 ; \mathrm{p}=0.005$; adjusted $\mathrm{r}$-squared $=0.52)$. The result with the $50 \%$ relative poverty measure is consistent.

I turn now to the comparison among the US states. Table 6 shows the results with life expectancy as outcome: 
Table 6 - Effect of Income Inequality and Poverty on Life Expectancy (USA)

\begin{tabular}{lllll}
\hline Life Expectancy & Model 1 & Model 2 & Model 3 & Model 4 \\
\hline Income Inequality & $-29.826^{* * *}$ & & -5.191 & 17.185 \\
& $(8.434)$ & & $(9.909)$ & $(30.508)$ \\
Poverty & & $-0.279^{* * *}$ & $-0.256^{* * *}$ & 0.698 \\
& & $(0.051)$ & $(0.068)$ & $(1.231)$ \\
Inequality $\times$ Poverty & & & -2.066 \\
& & & & $(2.662)$ \\
Constant & $90.330^{* * *}$ & $80.357^{* * *}$ & $82.395^{* * *}$ & $72.119^{* * *}$ \\
& $(3.767)$ & $(0.624)$ & $(3.940)$ & $(13.822)$ \\
Adjusted R2 & 0.19 & 0.38 & 0.37 & 0.36 \\
$\mathrm{~N}$ & 50 & 50 & 50 & 50 \\
\hline Note: SE in parenthesis; ${ }^{*} p<0.05 ; * * p<0.01 ; * * * p<0.001$ (two-tailed t-tests).
\end{tabular}

The results for the US states are substantially different: in fact, the interaction term is not significant in Model 4; poverty is significant and negatively associated with the outcome in Model 3, while the effect of inequality is instead nonsignificant in that model. In contrast to the argument of Wilkinson and Pickett (2009), here poverty rules out inequality: Model 2 is best, explaining twice as much variation as explained by Model 1. There is no need for visual representation.

Table 7 shows the results with the index of HSP as the outcome, which are perfectly consistent with those just seen: poverty replaces inequality as the explanation, and Model 2 represents the best fit, explaining $48 \%$ of the variation (15\% more than Model 1). For the US then, the relationship between income inequality and the two outcomes considered (life expectancy and health and social ills) is spurious, once absolute poverty is taken into account. The results are quite similar with the ratio p90/p10, whose effect is actually weaker than the Gini index. 
Table 7 - Effect of Income Inequality and Poverty on the Index of HSP (USA)

\begin{tabular}{lllll}
\hline Index of HSP & Model 1 & Model 2 & Model 3 & Model 4 \\
\hline Income Inequality & $20.658^{* * *}$ & & 7.906 & -9.453 \\
& $(4.077)$ & & $(4.683)$ & $(14.256)$ \\
Poverty & & $0.168^{* * *}$ & $0.132^{* * *}$ & -0.607 \\
& & $(0.025)$ & $(0.032)$ & $(0.575)$ \\
Inequality $\times$ Poverty & & & 1.603 \\
& & & & $(1.244)$ \\
Constant & $-9.219^{* * *}$ & $-2.008^{* * *}$ & $-5.111^{* *}$ & 2.860 \\
& $(1.821)$ & $(0.303)$ & $(1.862)$ & $(6.459)$ \\
Adjusted R2 & 0.33 & 0.48 & 0.50 & 0.51 \\
$\mathrm{~N}$ & 50 & 50 & 50 & 50 \\
\hline Note: SE in parenthesis; ${ }^{*} p<0.05 ; * * p<0.01 ; * * * p<0.001$ (two-tailed t-tests).
\end{tabular}

\section{Discussion}

The goal of this paper was to control the relationship between income inequality and health and societal outcomes found by Wilkinson and Pickett (2009) in order to assess (1) its possible spuriousness, (2) the role of poverty - ruled out as alternative explanation by the authors -, and (3) possible interactions between inequality and poverty, suggested by the analysis of previous work on the topic. I focused in particular on two outcomes, life expectancy and the index of health and social problems, which yielded comparable results. In summary, I found a significant and adverse effect of the interaction between poverty and inequality in the comparison across countries: inequality negatively affects life expectancy only in high-poverty countries, and does not affect it in low-poverty countries; inequality positively affects the index of health and social problems in all countries, but its effect is much stronger in the countries with high poverty. As for the comparison among US states, poverty has a significant and adverse effect on both outcomes, and when poverty is taken into account, the effect of inequality is nonsignificant.

The results of my analysis are on one hand somewhat compatible with some arguments advanced by Wilkinson and Pickett (2009); on the other hand, they cast doubt on the idea of inequality as a theory of everything. They are compatible in the following sense. Despite their core claim is that equality is better for everyone, the authors make some distinctions, recognizing that "health and social problems are more common among 
the less well-off within each society" and that "the overall burden of these problems is much higher in more unequal societies" (Wilkinson \& Pickett, 2009, p. 20). This resembles my first hypothesis, which finds empirical support at the international level, but the authors, not having a measure of poverty in their data set, cannot really test it. The unidimensionality of the effect of inequality must be, in any case, reconsidered, given its interaction with the poverty rate. The interaction suggests that inequality and poverty can worsen or lessen their reciprocal effect: using a legal metaphor, one could say that high inequality is an aggravating circumstance that exacerbates the effects of high poverty, while low poverty is a mitigating circumstance that alleviates the effects of high inequality.

Instead, the robust findings within the US states say something different, and are in sharp contrast with the main thesis of The Spirit Level. As said above, testing the relationship between two variables in different contexts does not represent a true control. However, Wilkinson and Pickett (2009) move from the country- to the state-level with the intention of checking the spuriousness of the effect of inequality, and they claim that the check is positive. In this analysis, by way of contrast, the spuriousness is checked at both levels: while at the country-level poverty does not replace, but interacts with inequality, at the state-level poverty cancels out inequality, confirming hypothesis 2. Using 1990 data, Kennedy et al. (1996) find that the association between inequality and mortality remains after adjustment for poverty. With 1999 data, the relationship between inequality and life expectancy/index of HSP among the US states is spurious. Given the remarkable US poverty rate, it is possible that absolute poverty just within the least well off affects the aggregate population measures overall. If that is correct, the absolute income argument finds support over the relative one in the US context. Many studies (Banks, Marmot, Oldfield, \& Smith, 2006, 2009; Subramanian \& Kawachi, 2006) show, however, that inequality affects the majority of the population. These two points are not necessarily incompatible: in fact, I argue that inequality and poverty can be distinguished but are interdependent, and their effects can rule each other out (as among the US states), or coexist and interact (as across countries), depending on the context and the particular shapes that inequalities assumes. Indeed, it seems plausible that the relationship between income distribution and health may not be universal, and may vary across different geographic contexts.

This study has some limitations. First, as was also true of The Spirit Level, it is cross-sectional. Second, in the different contexts I use different measures of poverty: 
relative poverty across countries, and absolute poverty across states. I addressed this point but I cannot exclude the possibility that the different results found in the two contexts might depend on the nature of the poverty measure. Third, these measures reveal a partial picture of poverty, because they only consider income. Fourth, I cannot advance claims about the mechanisms.

It is not my intention to dismiss altogether the importance of inequality: as Jencks put it, "the social consequences of economic inequality are sometimes negative, sometimes neutral, but seldom - as far as I can discover - positive" (Jencks, 2002, p. 64). The evidence here relates to a body of literature that shows the importance of poverty also in the richer world (Ludwig et al., 2011, 2012; Fritzell et al., 2013), and suggests that, in order to improve health and ameliorate social ills, raising the living standard is still a crucial task in the more affluent countries, not just in the poorer ones as Wilkinson and Pickett (2009) suggest. Poverty still matters, and sometimes it matters more than inequality. Furthermore, by looking at their statistical interaction, here I propose a formal way to assess the extent to which poverty matters along with inequality. To my knowledge, this is new to the literature: future research might want to further investigate this interaction, check its existence and robustness, and see in different contexts how the effect of inequality varies accordingly to the level of poverty. Here, combining OLS regressions and graphical visualization, it was possible to show the detrimental and significant effect of the interaction, and the change of the effect of inequality from high- to low-poverty countries. This suggests that despite being undoubtedly confounded, inequality and poverty are two different social issues. Policies that aim to improve health and ameliorate social ills should address both. 


\section{References}

Adler, N. E., Boyce, T., Chesney, M. A., Cohen, S., Folkman, S., Kahn, R. L., \& Syme, S. L. (1994). Socioeconomic status and health: the challenge of the gradient. American Psychologist, 49(1), 15-24.

Adler, N. E., \& Newman, K. (2002). Socioeconomic disparities in health: pathways and policies. Health Affairs, 21(2), 60-76.

Alcock, P. (2006). Understanding poverty. Palgrave Macmillan.

Banks, J., Marmot, M., Oldfield, Z., \& Smith, J. P. (2006). Disease and disadvantage in the United States and in England. Jama, 295(17), 2037-2045.

Banks, J., Marmot, M., Oldfield, Z., \& Smith, J. P. (2009). The SES health gradient on both sides of the Atlantic. In Developments in the Economics of Aging (pp. 359406). University of Chicago Press.

Barry, B. (1998). Social exclusion, social isolation and the distribution of income. London School of Economics: Centre for Analysis of Social Exclusion. Retrieved from http://eprints.lse.ac.uk/6516/

Barry, B. (2002). Social exclusion, social isolation and the distribution of income. In Understanding Social Exclusion. Oxford University Press.

Beckfield, J. (2004). Does Income Inequality Harm Health? New Cross-National Evidence. Journal of Health and Social Behavior, 45(3), 231-248.

https://doi.org/10.1177/002214650404500301

Booth, R. (2010). The Spirit Level: how "ideas wreckers" turned book into political punchbag. The Guardian. Retrieved from http://www.theguardian.com/books/2010/aug/14/the-spirit-level-equalitythinktanks

Bradshaw, J., \& Finch, N. (2003). Overlaps in dimensions of poverty. Journal of Social Policy, 32(04), 513-525.

Brady, D. (2003). Rethinking the sociological measurement of poverty. Social Forces, $81(3), 715-751$.

Dahl, E., Ivar Elstad, J., Hofoss, D., \& Martin-Mollard, M. (2006). For whom is income inequality most harmful? A multi-level analysis of income inequality and mortality in Norway. Social Science $\&$ Medicine, 63(10), 2562-2574.

Davey Smith, G. (1996). Income inequality and mortality: why are they related? BMJ, 312(7037), 987. 
Devich, M. (2010). The Spirit Level: Britain's new theory of everything? BBC News. Retrieved from http://www.bbc.co.uk/news/uk-politics-11518509

De Vogli, R., Mistry, R., Gnesotto, R., \& Cornia, G. A. (2005). Has the relation between income inequality and life expectancy disappeared? Evidence from Italy and top industrialised countries. Journal of Epidemiology and Community Health, 59(2), 158-162. https://doi.org/10.1136/jech.2004.020651

Elgar, F. J. (2010). Income inequality, trust, and population health in 33 countries. American Journal of Public Health, 100(11), 2311. https://doi.org/10.2105/AJPH.2009.189134

Elgar, F. J., \& Aitken, N. (2011). Income inequality, trust and homicide in 33 countries. The European Journal of Public Health, 21(2), 241-246. https://doi.org/10.1093/eurpub/ckq068

Elstad, J. I., Dahl, E., \& Hofoss, D. (2006). Associations between relative income and mortality in Norway: a register-based study. The European Journal of Public Health, 16(6), 640-644.

Equality Trust Website. (n.d.). Notes on statistical sources and methods. Retrieved May 31, 2014, from http://www.equalitytrust.org.uk/resources2/spirit-level/methods

Esping-Andersen, G. (1990). The Three Worlds of Welfare Capitalism. Princeton, N.J: Princeton University Press.

Finch, N., \& Bradshaw, J. (2003). Core poverty. Journal of Social Policy, 32(4), 513-526.

Fritzell, J., Kangas, O., Bacchus Hertzman, J., Blomgren, J., \& Hiilamo, H. (2013). Crosstemporal and cross-national poverty and mortality rates among developed countries. Journal of Environmental and Public Health, 2013. https://doi.org/10.1155/2013/915490

Gerdtham, U.-G., \& Johannesson, M. (2004). Absolute income, relative income, income inequality, and mortality. Journal of Human Resources, 39(1), 228-247.

Goldthorpe, J. H. (2010). Analysing social inequality: a critique of two recent contributions from economics and epidemiology. European Sociological Review, 26(6), 731-744.

Guetzkow, J., Western, B., \& Rosenfeld, J. (2007). State-Level Data on Income Inequality 1963-2003. Retrieved September 15, 2014, from http://inequalitydata.org/

Jencks, C. (2002). Does Inequality Matter? Daedalus, 131(1), 49-65. 
Kaplan, G. A., Pamuk, E. R., Lynch, J. W., Cohen, R. D., \& Balfour, J. L. (1996).

Inequality in income and mortality in the United States: analysis of mortality and potential pathways. BMJ, 312(7037), 999-1003.

https://doi.org/10.1136/bmj.312.7037.999

Kawachi, I., \& Berkman, L. F. (2000). Social Cohesion, Social Capital, and Health. In L.

F. Berkman \& I. Kawachi (Eds.), Social Epidemiology (pp. 174-190). Oxford: Oxford University Press.

Kawachi, I., \& Kennedy, B. P. (1997). The relationship of income inequality to mortality: does the choice of indicator matter? Social Science \& Medicine, 45(7), 1121-1127. https://doi.org/10.1016/S0277-9536(97)00044-0

Kawachi, I., Kennedy, B. P., Lochner, K., \& Prothrow-Stith, D. (1997). Social capital, income inequality, and mortality. American Journal of Public Health, 87(9), 14911498.

Kawachi, I., Subramanian, S. V., \& Almeida-Filho, N. (2002). A glossary for health inequalities. Journal of Epidemiology and Community Health, 56(9), 647-652.

Kennedy, B. P., Kawachi, I., Glass, R., \& Prothrow-Stith, D. (1998). Income distribution, socioeconomic status, and self rated health in the United States: multilevel analysis. BMJ, 317(7163), 917-921.

Kennedy, B. P., Kawachi, I., \& Prothrow-Stith, D. (1996). Income distribution and mortality: cross sectional ecological study of the Robin Hood index in the United States. BMJ, 312(7037), 1004-1007.

Kenworthy, L. (2011). Progress for the Poor. Oxford University Press.

Kenworthy, L., \& Pontusson, J. (2005). Rising inequality and the politics of redistribution in affluent countries. Perspectives on Politics, 3(03), 449-471.

Kondo, N., Sembajwe, G., Kawachi, I., van Dam, R. M., Subramanian, S. V., \& Yamagata, Z. (2009). Income inequality, mortality, and self rated health: metaanalysis of multilevel studies. BMJ: British Medical Journal, 339. https://doi.org/10.1136/bmj.b4471

Layard, R., Mayraz, G., \& Nickell, S. (2010). Does relative income matter? Are the critics right?. Oxford University Press.

Layte, R. (2012). The association between income inequality and mental health: testing status anxiety, social capital, and neo-materialist explanations. European Sociological Review, 28(4), 498-511. https://doi.org/10.1093/esr/jcr012 
Leigh, A., Jencks, C., Smeeding, T., Salverda, W. N. B., \& Smeeding, T. M. (2009). Health and economic inequality. The Oxford Handbook of Economic Inequality, $384-405$.

Levitas, R. (2005). The inclusive society?: social exclusion and New Labour. Palgrave Macmillan Basingstoke.

Lister, R. (2004). Poverty. Cambridge: Polity Press.

Lorgelly, P. K., \& Lindley, J. (2008). What is the relationship between income inequality and health? Evidence from the BHPS. Health Economics, 17(2), 249-265.

Ludwig, J., Duncan, G. J., Gennetian, L. A., Katz, L. F., Kessler, R. C., Kling, J. R., \& Sanbonmatsu, L. (2012). Neighborhood effects on the long-term well-being of lowincome adults. Science, 337(6101), 1505-1510. https://doi.org/10.1126/science.1224648

Ludwig, J., Sanbonmatsu, L., Gennetian, L., Adam, E., Duncan, G. J., Katz, L. F., ... Whitaker, R. C. (2011). Neighborhoods, obesity, and diabetes - a randomized social experiment. New England Journal of Medicine, 365(16), 1509-1519. https://doi.org/10.1056/NEJMsa1103216

Lynch, J., Davey Smith, G., Harper, S. A., Hillemeier, M., Ross, N., Kaplan, G. A., \& Wolfson, M. (2004). Is income inequality a determinant of population health? Part 1. A systematic review. Milbank Quarterly, 82(1), 5-99.

Marmot, M. G., Stansfeld, S., Patel, C., North, F., Head, J., White, I., ... Davey Smith, G. (1991). Health inequalities among British civil servants: the Whitehall II study. The Lancet, 337(8754), 1387-1393.

Massey, D. S., \& Denton, N. (1993). American apartheid: Segregation and the making of the underclass. Harvard University Press.

Mellor, J. M., \& Milyo, J. (2002). Income inequality and health status in the United States: Evidence from the Current Population Survey. Journal of Human Resources, 37(3), 510-539.

Mullahy, J., Robert, S., \& Wolfe, B. (2008). Health, income, and inequality. In D. B. Grusky (Ed.), Social Stratification: Class, Race, and Gender in Sociological Perspective (3rd ed., pp. 904-915). Boulder: Westview Press.

Pickett, K. E., \& Wilkinson, R. G. (2015). Income inequality and health: A causal review. Social Science \& Medicine, 128, 316-326. https://doi.org/10.1016/j.socscimed.2014.12.031 
Preston, S. H. (1975). The changing relation between mortality and level of economic development. Population Studies, 29(2), 231-248.

Quenouille, M. H. (1949). Problems in plane sampling. The Annals of Mathematical Statistics, 20(3), 355-375.

Quenouille, M. H. (1956). Notes on bias in estimation. Biometrika, 43(3-4), 353-360.

Reardon, S. F., \& Bischoff, K. (2011). Income Inequality and Income Segregation. American Journal of Sociology, 116(4), 1092-1153.

Ringen, S. (1986). Poverty in the Welfare State? International Journal of Sociology, 122138.

Rodgers, G. B. (1979). Income and inequality as determinants of mortality: an international cross-section analysis. Population Studies, 33(2), 343-351.

Soobader, M.-J., \& LeClere, F. B. (1999). Aggregation and the measurement of income inequality: effects on morbidity. Social Science 83 Medicine, 48(6), 733-744.

Subramanian, S., \& Kawachi, I. (2006). Whose health is affected by income inequality? A multilevel interaction analysis of contemporaneous and lagged effects of state income inequality on individual self-rated health in the United States. Health $\varepsilon^{3}$ Place, 12(2), 141-156.

Supplementary Benefit Commission in Britain. (1979). Annual Report 1978. London: HMSO.

Townsend, P. (1962). The meaning of poverty. British Journal of Sociology, 210-227.

Townsend, P. (1987). Deprivation. Journal of Social Policy, 16(02), 125-146.

Tukey, J. W. (1958). Bias and confidence in not-quite large samples. Annals of Mathematical Statistics, 29, 614-614.

Wilkinson, R. G. (1992). Income distribution and life expectancy. BMJ, 304(6820), 165168.

Wilkinson, R. G., \& Pickett, K. E. (2009). The Spirit Level: Why Equality is Better for Everyone. London: Penguin UK.

Wilson, W. J. (1987). The Truly Disadvantaged: The Inner City, the Underclass, and Public Policy, Second Edition. University of Chicago Press.

Wood, A. M., Boyce, C. J., Moore, S. C., \& Brown, G. D. (2012). An evolutionary based social rank explanation of why low income predicts mental distress: A 17 year cohort study of 30,000 people. Journal of Affective Disorders, 136(3), 882-888. 